\title{
MARKET RISK MANAGEMENT FOR PUBLIC UTILITIES THROUGH AHP
}

\author{
Massimo Fuccaro \\ Department of Electrical, Management and Mechanical Engineering \\ University of Udine, Italy \\ E-mail: massimo.fuccaro@uniud.it \\ Patrizia Simeoni * \\ Department of Electrical, Management and Mechanical Engineering \\ University of Udine, Italy \\ E-mail: patrizia.simeoni@uniud.it \\ Fabio De Felice \\ Department of Civil and Mechanical Engineering \\ University of Cassino, Italy \\ E-mail: defelice@unicas.it
}

\begin{abstract}
Quantitative and qualitative models exist for the evaluation of financial risk. Some evaluation models are based on requiring either inputs of historical data or expert opinions.

In this paper, we have evaluated the risk in an investment portfolio of a public utilities company in the region of Friuli Venezia Giulia, North East of Italy. For the evaluation, the AHP, a classic model proposed by Saaty, has been used, recognising the hierarchy structure in criteria and sub-criteria defined by the experiences of sector operators and compared with pairs.

Five portfolios proposed by financial promoters and five obtained randomly have been compared, considering the knowledge and preferences of the company managers and a level of risk equal to the level proposed by banks.

We consider the affiliation sector of the portfolio titles and the geography, meaning the Country of emission of titles, to analyse country risk and the currency of issue of titles to analyse exchange rate risk.

For each criterion, experts evaluated sub-criteria. To identify the weights of both algorithms related to the differentiation of titles within a portfolio and to identify the criteria based on the socioeconomic knowledge within a financial framework, experts relied on involved operators.

The flexibility of this instrument translates into the ability to use this instrument to consider either qualitative aspects of the risk or quantitative and semi quantitative aspects. The instrument can be considered a usual instrument in the management of public utilities companies, as long as the instrument is linked to the knowledge of managers.
\end{abstract}

Keywords: AHP, risk management, portfolios, public utilities, VAR

\section{Introduction}

In the last few years, the globalisation of the financial markets, the intensification of competition, and rapid changes in social, economic and technologic frameworks increased insecurity in the financial industry.

\footnotetext{
${ }^{*}$ Corresponding author
} 
For this reason, some methods of optimisation and simulation of decision supporting systems have become necessary instruments to support financial decision-making.

Literature since the 1950s has contributed insights on the methods of selecting and managing portfolios for investments of venture capital, for bankruptcy forecasts, for financial planning and for strategising the mergers and acquisitions of companies (Zopounidis, 1999). Financial planning modelling is based on three specific elements: the consideration of a variety of conflicting decisional criteria, a general evaluation process and the identification of the presence of different operators in the evaluation and selection process (financial analysts, portfolio managers and investors). Making a decision in the financial industry might be more similar to an 'analysis multi-attribute' (MCDA) approach than to an 'identifying an optimal solution' approach for three reasons. First, if we consider the approach of 'identifying an optimal solution,' we constrain a decision-maker to a very narrow perspective, which is often not connected with the real nature of problems faced by the decision-maker's company or by the 'company core'. Second, financial decisions are made by managers and not by mathematical models. Third, considering the large number of both internal and external variables that relate to deciding between different investment portfolios, discussions about the 'optimal solution' are moot. The most important contribution of the MCDA method is that managers can be actively involved in the process, without being experts, which supports their ability to comprehend the dynamics and peculiar features of the problems that they are facing. In this way, managers are not limited to passive roles of automatically adopting supposed optimal solutions obtained by mathematic models. On the contrary, managers are directly involved in the process by sharing their opinions.

Zopounidis and Doumpos (2002) studies detected that many methods of multi-criteria analysis are used to solve two peculiar problems that exist in the financial sector: the investment decision and the portfolio management decision.

Some authors focused on a multi-objectives approach, whereas (Arenas Parra et al., 2001) others focused on multi-attributes (Dominiak 1997; Jog et al.,1999; Hurson and Zopounidis; 1995), applying mainly PROMETHEE and ELECRE methods. Only one paper, Saaty (1980), applies the AHP method to the financial sector.

Additionally, Steuer and $\mathrm{Na}$ (2003) broadly review the methods of multi-criteria analysis associated with financial decisions taking into consideration 265 papers on the topic. Comparing the studies considered in our review, we found that AHP method to the management of portfolios has only been analysed and applied in one other paper (Jensen, 1987).

Focusing on the AHP method, Michnick et al. (2005) has been used to quantify, monitor, and control financial risk with the aim of improving financial performances in a framework of volatility and market globalisation. They focused on bankruptcy and credit risk assessments, portfolio selection and management selections, corporate performance evaluations, investment appraisals, and other financial decision-making problems.

Lee and Cheng (2008) apply the AHP method to evaluate the risk of HYB (High-yield bond) with quantitative criteria (Spread, the Bond call ability and rate of default).

$\mathrm{Xu}$ and Zhang (2008) propose a new evaluation method for online credit based on AHP models and SPAs (Set Pair Analysis) taking into consideration either qualitative or quantitative criteria. Bhattarai and Yadav (2009) focus on the utilisation of the AHP model in the banking sector in the context of a global financial crisis and validate the use of such a method as an instrument for decision support systems for use by the banking sector in Nepal.

In this paper, we propose the evaluation of risk for an investment portfolio of a public utilities company, a S.p.A., based on using the Analytic Hierarchy Process (AHP) as a guiding framework. The following section describes our case study. Then, our analysis and discussion of the findings are provided in section 3. Finally, some concluding remarks are given. 


\section{P. Simeoni Et Al./ Market risk management for public utilities}

\section{The case study}

The paper reflects the need of a public utilities company in the environmental sector to properly manage its financial portfolio in light of difficulties in selecting less risky solutions than the solutions proposed by local financial operators. We consider a 'low risk' solution to be a solution that is relatively removed from financial speculation and still guarantees a remuneration of the investment principal. Such an investment would have a risk profile that would be justifiable and that could be approved by citizens because this type of investment is essentially an investment of public money.

In Italy, banks and financial organisations have identified four types of portfolios: conservative, moderate, dynamic and active. Each of these portfolio types is characterised by a different appetite for risk, which is evaluated by the $\mathrm{VaR}$ (Value at Risk) of the portfolio. The VaR is the maximum estimated percentage of loss of the invested capital after a certain period of time given the probability of loss assigned to the investment.

As shown in Table 1, a profile of a conservative investment refers to a portfolio with a VaR between $0 \%$ and $5 \%$, inclusive. A moderate portfolio and a dynamic portfolio have VaRs between $5.01 \%$ and $10 \%$, inclusive, and between 25.01 and 50\%, inclusive, respectively.

The same table shows the indicative percentages of the compositions of the profiles (cash, actions and obligations) and underlines a migration of cash and obligations towards actions as the VaR increases.

Table 1. The classification of portfolios based on VARs for a period of 3 months and at a confidence interval of $99 \%$.

\begin{tabular}{|l|c|c|c|c|}
\hline Portfolio & VAR & Current assets & Bond & Equity \\
\hline Conservative & $0 \%-5 \%$ & $10-30 \%$ & $45-55 \%$ & $10-20 \%$ \\
\hline Moderate & $5.01 \%-10 \%$ & $0-15 \%$ & $50-60 \%$ & $30-45 \%$ \\
\hline Dynamic & $10.01 \%-25 \%$ & $0-6 \%$ & $30-40 \%$ & $55-65 \%$ \\
\hline Active & $25.01 \%-50 \%$ & $0 \%$ & $0 \%$ & $100 \%$ \\
\hline
\end{tabular}

In a moderate portfolio with a $\mathrm{VaR}$ of $5 \%$ and at a confidence level of $99 \%$, the maximum potential loss of the portfolio over a period of three months is $5 \%$. However, the portfolio is also subject to a $1 \%$ probability of suffering a loss higher that $5 \%$.

The company received five offers from national banks $(\mathrm{P} 1 \rightarrow \mathrm{P} 5)$ for an investment portfolio of $10 \mathrm{M} €$ with a moderate risk level (VaR 5-10\%). The offers received are summarised in Table 2.

Table 2. The securities in the portfolios offered by the five financial institutions.

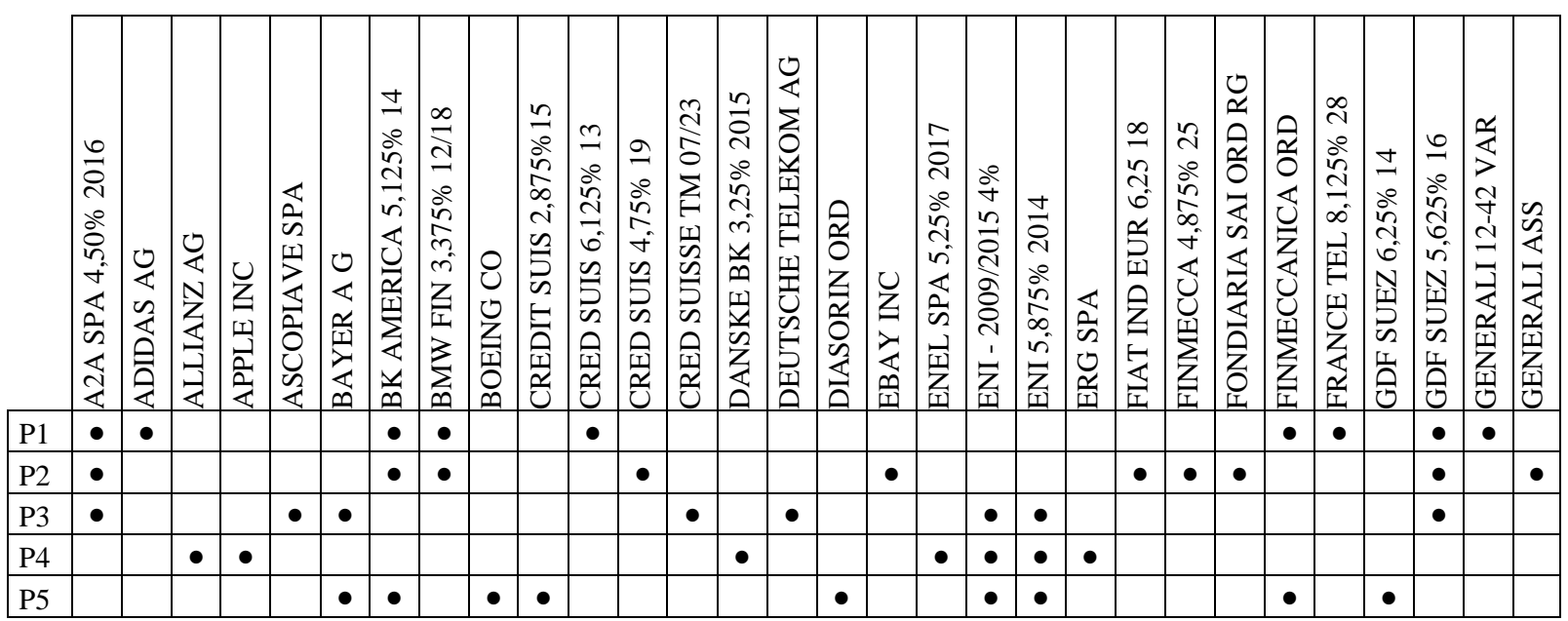




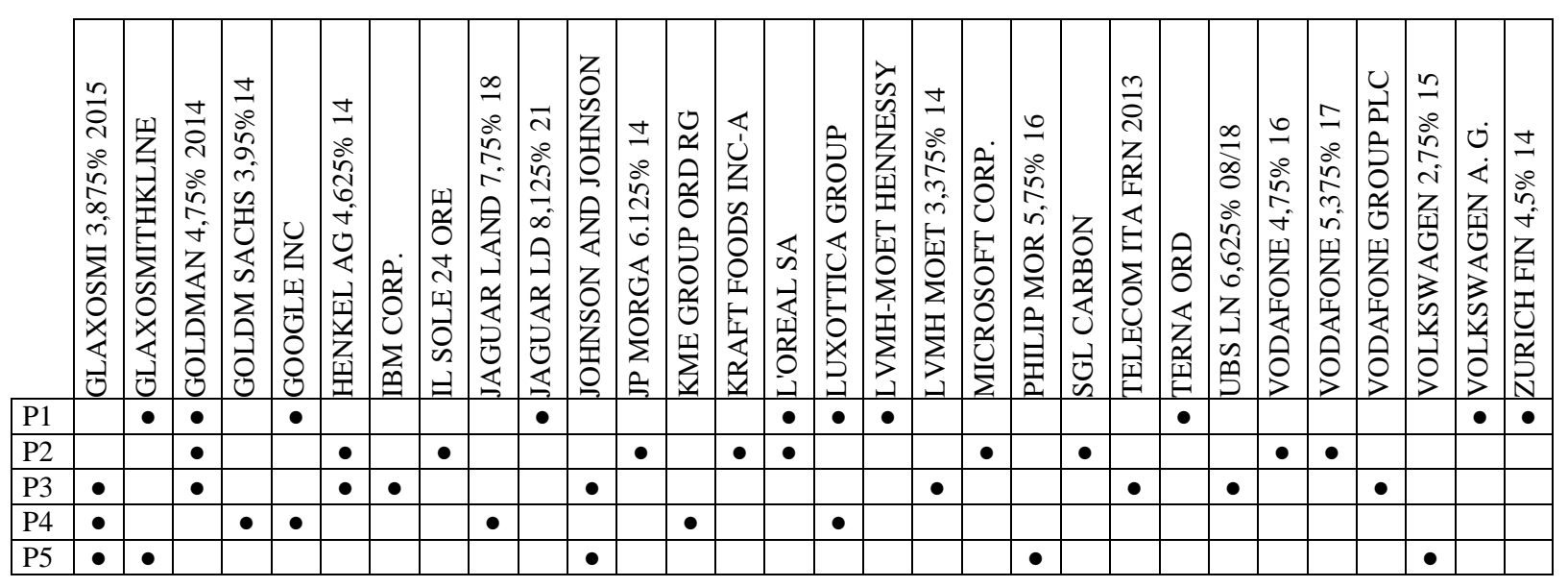

A comparison of the different portfolios reveals that banks immediately divided their available budgets for the investment into $38.46 \%$ of actions and $61.54 \%$ of obligations.

By analysing the stocks of the packages according to sectors (Table 3), a banking institution would propose titles within the sector of consumer goods (cars and car components, food, fashion, household products and personal products), financial products (banking, insurance, real estate, and financial services), oil and natural gas, and health.

Four out of five banking institutions proposed titles within the following sectors: chemical; raw materials; consumption services; trade; media; travel and entertainment; and technology. Titles within the industrial and communication sectors have been considered by three out of five banks, and only one proposed titles within the consumption services sector. Assembling titles by geographical area, we can observe that the proposed packages are from the following countries: Germany, France, the United Kingdom, Italy, Switzerland, and the U.S.A. The currencies in the packages are the euro, the British pound, the Swiss Franc and the American Dollar.

Table 3. The sector of the stocks in the portfolios offered by the five banks.

\begin{tabular}{|c|c|c|c|c|c|c|c|c|c|c|}
\cline { 2 - 10 } \multicolumn{1}{c|}{} & $\begin{array}{c}\text { Consumer } \\
\text { goods }\end{array}$ & $\begin{array}{c}\text { Chemistry, } \\
\text { raw } \\
\text { materials }\end{array}$ & Finance & Industry & $\begin{array}{c}\text { Oil/natural } \\
\text { gas }\end{array}$ & Health & Services & $\begin{array}{c}\text { Public } \\
\text { utilities }\end{array}$ & Technology & $\begin{array}{c}\text { Telecom- } \\
\text { munications }\end{array}$ \\
\hline P1 & $\bullet$ & & $\bullet$ & $\bullet$ & $\bullet$ & $\bullet$ & & $\bullet$ & $\bullet$ & $\bullet$ \\
\hline P2 & $\bullet$ & $\bullet$ & $\bullet$ & $\bullet$ & $\bullet$ & $\bullet$ & $\bullet$ & $\bullet$ & $\bullet$ & $\bullet$ \\
\hline P3 & $\bullet$ & $\bullet$ & $\bullet$ & & $\bullet$ & $\bullet$ & & $\bullet$ & $\bullet$ & $\bullet$ \\
\hline P4 & $\bullet$ & $\bullet$ & $\bullet$ & & $\bullet$ & $\bullet$ & & $\bullet$ & $\bullet$ & \\
\hline P5 & $\bullet$ & $\bullet$ & $\bullet$ & $\bullet$ & $\bullet$ & $\bullet$ & & & & $\bullet$ \\
\hline
\end{tabular}

The managers of the company have shown their interest in using their financial economic knowledge by creating five investment proposals that are compared with the investment proposals received from Banks. To create the portfolios the following methods have been used:

1. Managers selected a moderate risk profile for their portfolios and divided ten M€ investments into $44 \%$ (4.4 M€) actions and 5.6 M€ obligations.

2. Managers, according to their experiences and knowledge, created two samples of 50 titles each, one sample for actions and one sample for obligations.

3. Portfolios have been created through a random selection of titles from the samples according to an algorithm summarised in figure 1. Each random selection corresponds to the position of the title in the sample ordered alphabetically. Each random selection of an equivalent market for each title is a number between 3 and 8 , inclusive, corresponding to the equivalent markets in table 4 given by managers to sustain and harmonise the composition of the portfolios with the amount of titles and the relative shares of titles. The creation of portfolios was completed by repeating the algorithms for 
actions and obligations until a final value was obtained.

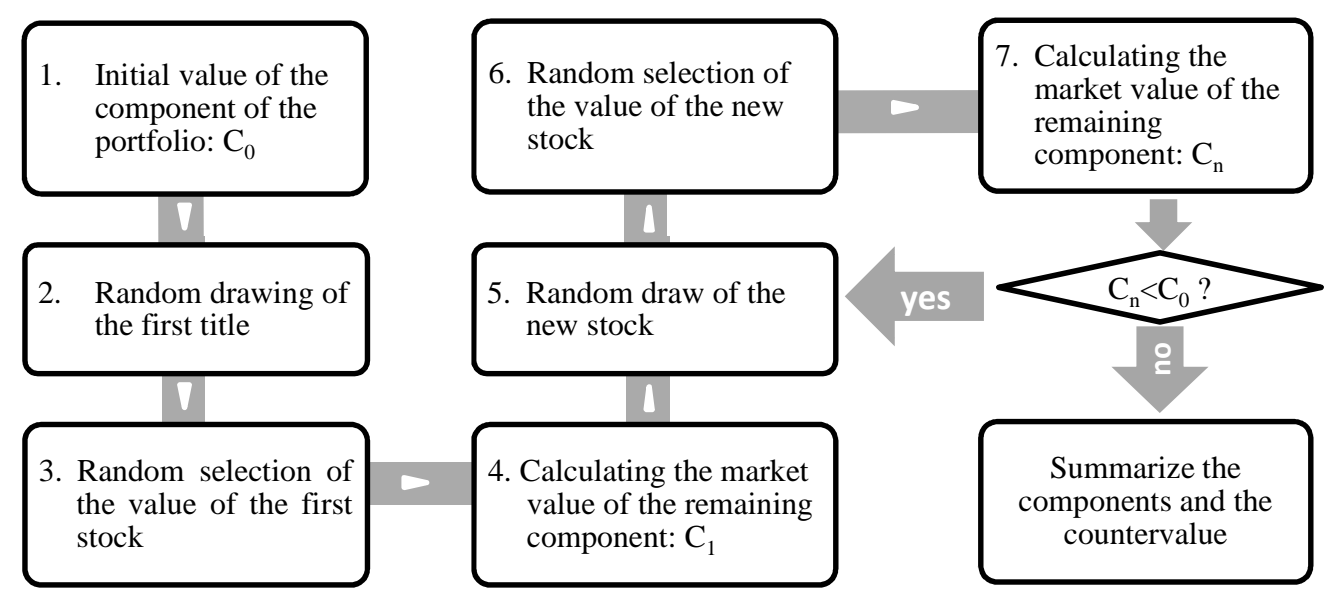

Figure 1. The method of composition of the equity and the bond portfolios.

Table 4. Counter-market random extraction.

\begin{tabular}{|c|c|}
\hline Number & Equivalent markets \\
\hline 3 & $300.000,00 €$ \\
\hline 4 & $400.000,00 €$ \\
\hline 5 & $500.000,00 €$ \\
\hline
\end{tabular}

\begin{tabular}{|c|c|}
\hline Number & Equivalent markets \\
\hline 6 & $600.000,00 €$ \\
\hline 7 & $700.000,00 €$ \\
\hline 8 & $800.000,00 €$ \\
\hline
\end{tabular}

Portfolios created by managers are summarised in Table 5 .

Table 5. The stocks in the portfolios generated by corporate executives.

\begin{tabular}{|c|c|c|c|c|c|c|c|c|c|c|c|c|c|c|c|c|c|c|c|c|c|c|c|c|c|c|}
\hline & đ্ & 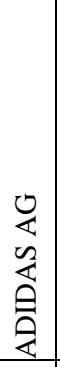 & 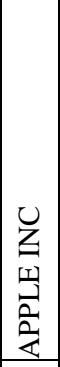 & 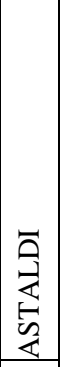 & 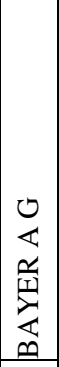 & 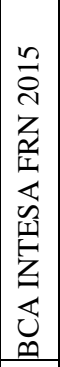 & 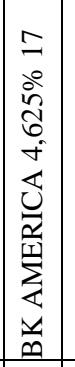 & 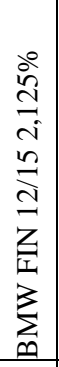 & 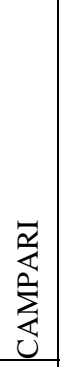 & 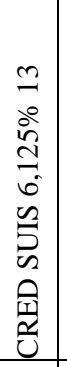 & 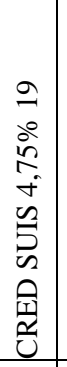 & 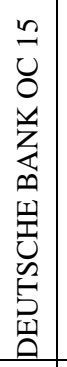 & 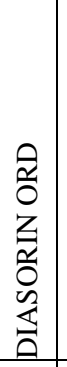 & 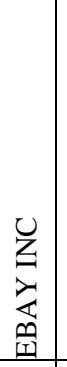 & 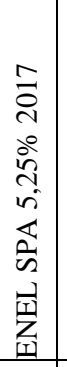 & $\begin{array}{l}\mathbb{a} \\
\vec{n} \\
0 \\
\tilde{w} \\
w\end{array}$ & 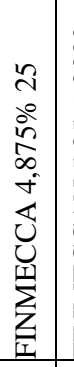 & 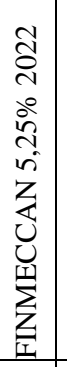 & 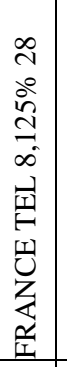 & 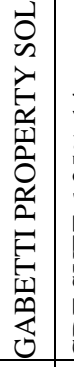 & 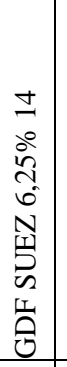 & 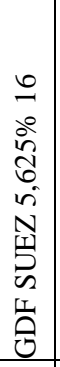 & 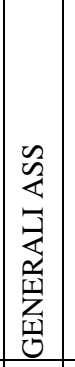 & 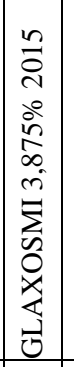 & 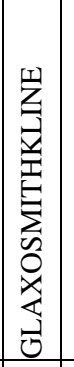 & 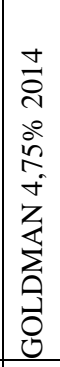 \\
\hline P6 & $\bullet$ & & & $\bullet$ & & $\bullet$ & \begin{tabular}{l|} 
\\
\end{tabular} & & $\bullet$ & & & & & $\bullet$ & $\bullet$ & & - & $\bullet$ & & $\bullet$ & & $\bullet$ & $\bullet$ & & & \\
\hline P7 & & & $\bullet$ & & $\bullet$ & & & & & $\bullet$ & $\bullet$ & & $\bullet$ & & $\bullet$ & & & & $\bullet$ & & $\bullet$ & $\bullet$ & & - & & \\
\hline P8 & $\bullet$ & $\bullet$ & & & $\bullet$ & & & $\bullet$ & & & & $\bullet$ & & $\bullet$ & & & & & & & & & & & & $\bullet$ \\
\hline P9 & & & & & & & & & & • & $\bullet$ & & & & & & & • & & & & & & & & \\
\hline $\mathrm{P} 10$ & & & & & & & & & & $\bullet$ & $\bullet$ & $\bullet$ & $\bullet$ & & & $\bullet$ & & & & & & & & $\bullet$ & $\bullet$ & \\
\hline
\end{tabular}




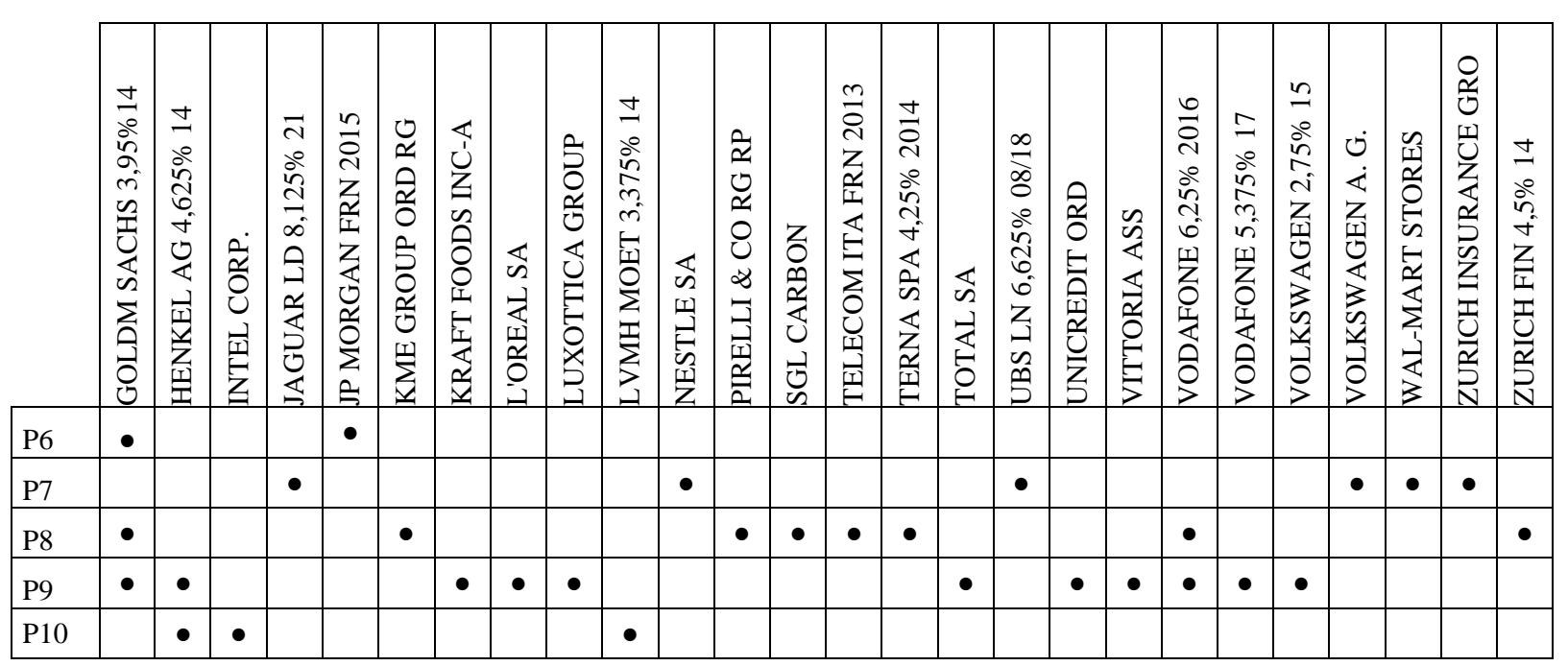

\section{Analysis model and results}

The AHP is a method of calculation based on 'pair comparing' in which priority scales are identified by the opinions of experts (Saaty, 2008). A decision is made by prioritising different possible solutions while taking into considerations qualitative and quantitative variables within a hierarchical structure (the goal of the problem on the top in light of the multiple criteria that define the alternatives on the middle and the alternatives on the bottom).

$\mathrm{C}=\left\{\mathrm{C}_{\mathrm{j}} \mid \mathrm{j}=1,2, \ldots, \mathrm{n}\right\}$ are the criteria. The result of the comparison of $n$ criteria can be summarised in a matrix of the valuation of reciprocal and square elements, where each element $a_{i j}(i, j=1, \ldots, n)$ is the quotient of the criteria weights.

If we multiply matrix A, as defined, by the weights vector, which represents the weight attributed to each one of the alternatives, we obtain the follow operation: $\mathrm{A} \cdot \mathrm{w}=\lambda_{\max } \cdot \mathrm{w}$, where $\lambda_{\max }$ is the automatic value of the matrix equal to dimension $n$.

If the matrix is consistent, then weights can be obtained through the normalisation of the rows and columns of A.

The consistency ratio (CR) that defines whether the matrix A is sufficiently consistent is calculated as the ratio of the $\mathrm{CI}$ and the random index (RI) (see Table 6). The value 0.1 is the accepted upper limit for the CR.

\section{$\mathrm{CR}=\mathrm{CI} / \mathrm{RI}$}

Table 6. Random Index [Saaty, 2008].

\begin{tabular}{|l|c|c|c|c|c|c|c|c|c|c|}
\hline $\mathbf{n}$ & 1 & 2 & 3 & 4 & 5 & 6 & 7 & 8 & 9 & 10 \\
\hline $\mathbf{R I}$ & 0.00 & 0.00 & 0.58 & 0.90 & 1.12 & 1.24 & 1.32 & 1.41 & 1.45 & 1.49 \\
\hline
\end{tabular}

\subsection{The model}

The step by step application of AHP model to the case study:

STEP 1. The dominance hierarchy is structured: (see Figure 2):

- Goal. The aim is to identify a portfolio proposal that is removed from financial speculation. Therefore, the solution is an investment portfolio that can guarantee a profit from investment, while preserving a low level of risk consistent with a public investment.

- Criteria. The criteria for analysis identified by company managers are: 
(A) the affiliation sector of the titles of portfolio; (B) the geography, meaning the Country of the emission of titles, to consider the evaluation of the socio-politic stability of the given country and an evaluation of the country risk; and (C) the currency of the issue of titles (C) to consider the exchange rate risk.

- Sub-criteria. The sub-criteria chosen by managers are the sectors of the Italian stock market:

(A.1) oil/ natural gas, (A.2) chemical sector and raw materials, (A.3, industry, (A.4) consumer goods (cars and car components, food, fashion, household products and personal products), (A.5) health, (A.6) consumption services (trade, media, travels and free time), (A.7) telecommunications, (A.8) public services (A.9) finance (banking, insurance, real estate, financial services) and (A.10) technology.

The considered countries are (B.1) France, (B.2) Germany, (B.3) Italy, (B.4) Switzerland, (B.5) United Kingdom, and (B.6) U.S.A. The fourth sub-criterion is currency: American (C.1) Dollar, (C.2) euro, (C.3) Swiss Franc, (C.4) British pound.

The criteria and sub-criteria selected by managers are in line with the criteria proposed by banks.

- Alternative. The alternatives being analysed are the ten portfolios mentioned above.

STEP 2. A matrix for pair comparing and evaluations scales has been created.

All of the elements belonging to the same hierarchical category are compared in pairs to establish which of them is the most important in relation to the element for a given scale of values.

The hierarchical structure composed needs three types of pair comparisons:

(1) a comparison between the criteria and the objective, (2) a comparison between the sub-criteria and the dominant criterion, and (3) a comparison between the sub-criteria and the alternatives.

The comparisons of verbal procedures has been made by taking into consideration the opinions of an expert group composed of company managers and five promoters of portfolios ( $\mathrm{P} 1 \rightarrow \mathrm{P} 5$ of Banks).

The experts opted for the semantic scale of Saaty (2008) that considers alternatives through percentages corresponding with the following categories: equally important, slightly important, important, much very important, extremely important defined as $1,3,5,7,9$, respectively.

For the first comparisons of pairs (criterion-objective and criterion-sub-criteria), experts formulated individual opinions that have not been aggregated by a geometric mean to obtain the relative importance of the comparisons of pairs.

To apply the scale of Saaty to the comparison of the sub-criteria with alternatives, the experts proceeded as follows:

- The identification of band membership. This sub-criterion was evaluated by noting the percentage of the incidence of the counter value of each sub-criterion with respect to the total investment of the portfolio and has been identified in the five bands shown, denoted as a, b, c, d and e in tab. 8 on the left. The band is wider than the other band in part because experts believe that when the threshold is exceeded by $40 \%$, the license has been particularly influential in the comparison.

- The assignment of the rating scale. Once the associated band membership for each sub-criteria has been determined, the alternatives were compared using the rating scale shown in Table 7 on the right which assigns a score from 1 (most risky) to 9 (least risky) for each band.

Table 7. The percentage ranges for the comparison of the criteria with the sub-criteria (on the left) and the rating scale between two alternatives with respect to sub-criteria $\mathrm{X}_{\mathrm{i}}$ (on the right).

\begin{tabular}{|c|c|c|}
\hline \% Min & \% Max & Band \\
\hline $40 \%$ & $100 \%$ & $a$ \\
\hline $30 \%$ & $40 \%$ & $b$ \\
\hline $20 \%$ & $30 \%$ & $c$ \\
\hline $10 \%$ & $20 \%$ & $d$ \\
\hline $0 \%$ & $10 \%$ & $e$ \\
\hline
\end{tabular}

\begin{tabular}{|c|c|c|c|c|c|}
\hline & $\mathbf{a}$ & $\mathbf{b}$ & $\mathbf{c}$ & $\mathbf{d}$ & $\mathbf{e}$ \\
\hline $\mathbf{a}$ & 1 & 3 & 5 & 7 & 9 \\
\hline $\mathbf{b}$ & & 1 & 3 & 5 & 7 \\
\hline $\mathbf{c}$ & & & 1 & 3 & 5 \\
\hline $\mathbf{d}$ & & & & 1 & 3 \\
\hline $\mathbf{e}$ & & & & & 1 \\
\hline
\end{tabular}


STEP 3. Weights and solutions have been considered using a bottom-up method, by calculating first the local weights which measure the importance of each element in relation to the relevant higher-level element (the sub-criteria, the criteria, and the goal), then calculating the global weights as a sum of the local weights by multiplying the weights of the higher-level elements to obtain an arrangement of portfolios and finally selecting the best portfolios.

For positive solutions, the value of the ratio of consistency is always lower than 0.1.

Weights as percentages are summarised in Figure 2.

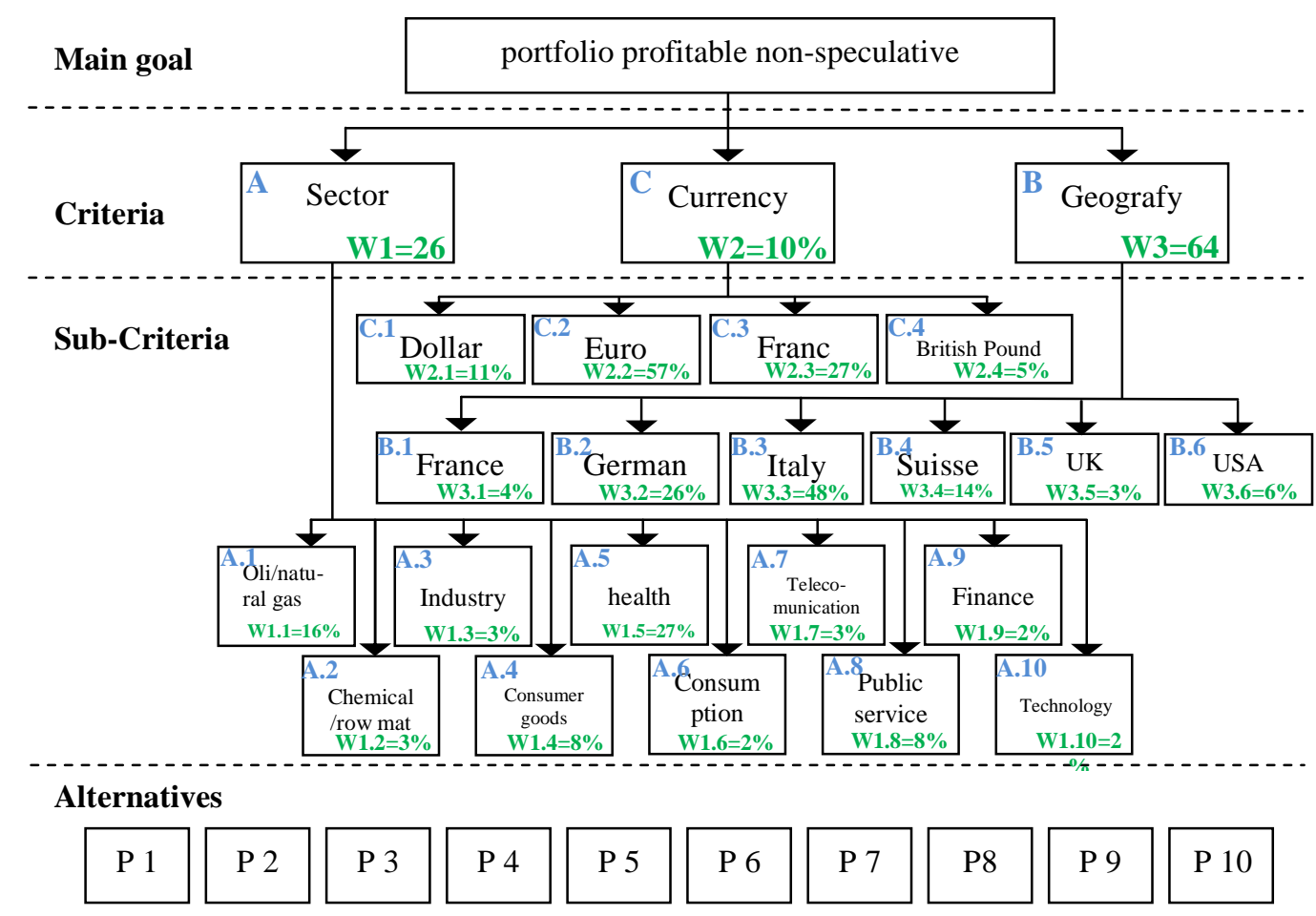

Figure 2. The reference system model used for the AHP and weights.

\subsection{Results}

The final order of the portfolios, from least risky to most risky, is shown in Table 8 . The best portfolio was one of the portfolios proposed by corporate executives, consisting of $40 \%$ of turnovers of securities belonging to the health sector with a predominance of English titles. The dominance of the currency of the securities issued is mainly divided between the euro and the sterling.

Table 8. The final rankings of the portfolios in accordance with the AHP model.

\begin{tabular}{|l|l|l|}
\hline Ranking & Portfoglio & Score AHP \\
\hline 1 & P10 & 0.12411 \\
\hline 2 & P4 & 0.12103 \\
\hline 3 & P3 & 0.11383 \\
\hline 4 & P7 & 0.10893 \\
\hline 5 & P5 & 0.10471 \\
\hline
\end{tabular}

\begin{tabular}{|l|l|l|}
\hline Ranking & Portfoglio & Score AHP \\
\hline 6 & P8 & 0.08901 \\
\hline 7 & P6 & 0.08659 \\
\hline 8 & P2 & 0.08575 \\
\hline 9 & P9 & 0.08426 \\
\hline 10 & P1 & 0.08179 \\
\hline
\end{tabular}




\section{Conclusion}

The latest global financial crisis has shown the lack of the ability of many organisations, such as banks and businesses, to manage financial risk correctly. The AHP can be used to help managers of public companies to select investment portfolios.

The use of the model by a profitable public company for the management of capital enables the management sort through portfolios based on risk, highlighting the usefulness of the AHP for developing a higher awareness of the financial risks associated with the investment of public money.

Financial risks have been evaluated creating investment packages by analysing titles in relation to the following criteria: affiliation sector, issued currency of, and the socio-political stability of the emission Country. Because of the flexibility of this instrument in considering qualitative aspects of risk or quantitative and semi quantitative aspects of risks, this instrument can be considered a useful instrument for the management of public utilities companies, as long as the instrument is used in connection with the knowledge of managers.

For the future, an integration of the three criteria analysed with existing quantitative methods would be an interesting undertaking. This integration could be achieved by considering further criteria such as risk indicators currently used to measure the sensitivity of a portfolio to changes in the market, such as movements in the Greek market.

\section{REFERENCES}

Arenas Parra, M., Bilbao Terol, A., Rodriguez Uria, M.V. (2001). A fuzzy goal programming approach to portfolio selection. European Journal of Operational Research, 133(2), 287-297.

Bhattarai, S., Yadav, S. R. (2009). AHP application in banking: unfolding utility in a situation of financial crisis. Proceedings ISAHP 2009.

Dominiak, C. (1997). Portfolio selection using the idea of reference solution. Multiple Criteria Decision Making, Proceedings of the Twelfth International Conference, Fandel G, Gal Th. (eds). Springer.

Jensen, R.E. (1987). International investment risk analysis: Extensions for multinational corporation capital budgeting models, Mathematical Modelling.

Hurson, Ch., Zopounidis, C. (1995). On the use of multicriteria decision aid methods to portfolio selection. Journal of Euro-Asian Management 1(2), 69-94.

Jog, V., Kaliszewski, I., Michalowski, W. (1999). Using attribute trade-off information in investment. Journal Multi-Criteria Decision Analysis, 8, 189-199.

Lee, C., Cheng, J. (2008). A fuzzy AHP application on evaluation of high-yield bond investment. WSEAS Transactions on Information Science and Applications, Vol. 5, Issue 6.

Michnik, J., Lo, M. (2005). Enhancement of financial risk management with the aid of Analytic Hierarchy Process. Proceedings ISAHP 2005.

Saaty, T.L., Rogers, P.C., Pell, R. (1980). Portfolio selection through hierarchies. The Journal of Portfolio Management.

Saaty, T.L. (2008). Decision Making With the Analytic Hierarchy Process. Int. J. Services Sciences, Vol. 1, No. 1 . 
Steuer, R. E., Na, P. (2003). Multiple criteria decision making combined with Finance. European Journal of Operational Research.

Xu, Y., Zhang, Y. (2008). A online credit evaluation method based on AHP and SPA, Elsevier B.V.

Zopounidis, C. (1999). Multi-criteria decision aid in financial management. European Journal of Operational Research.

Zopounidis, C., Doumpos, M. (2002). Multi-criteria decision aid in financial decision making: methodologies and literature review. Journal of Multi-Criteria Decision Analysis, 167-186. 